\title{
CONSERVACION DE FACHADAS EN DIVERSOS LUGARES DE MADRID/ESPAÑA
}

\author{
(CONSERVATION OF FRONTAGES ON SEVERAL PLACES IN MADRID)
}

$128-8$

\section{RESUMEN}

Como complemento del Tema de Fondo se presentan en esta sección cuatro obras que recogen algunas de las realizaciones más recientes en esta materia del vaciado de edificios conservando la fachada, tema cada vez más frecuente por la multitud de recientes disposiciones tendentes a conservar el patrimonio histórico-artístico de nuestras ciudades, y de gran complejidad por la especificidad de cada uno de los casos.

Con el conjunto de las cuatro obras se pretende reflejar algunos de los problemas que más comúnmente se presentan en este tipo de proyectos, y sus correctas soluciones.

La primera corresponde a un edificio de dos plantas con semisótano que, después de vaciado y reconstruido, se suplementa con otro cuerpo de cuatro alturas, de tratamiento totalmente distinto por disposiciones municipales.

La segunda obra está compuesta por dos edificios de uso muy distinto (fábrica de hielo y sus oficinas), realizados en épocas sucesivas y con diferente tratamiento constructivo, lo que ha obligado a soluciones distintas para cada cuerpo.

El tercer proyecto es una acción del ayuntamiento de Madrid, que actuó por ejecución sustitutoria dado el avanzado peligro de ruina de la edificación y la pasividad de la propiedad.

La última obra es un edificio de viviendas configurado en planta como una $L$, compuesto por 6 alturas sobre rasante y un sótano.

\section{SUMMARY}

As complement to the Main Subject this section presents four works which select some of the most recent facts about the emptying of buildings preserving their frontage. This subject is more and more frequent because of the multiplicity of the recent ordinances tending towards the preservation of the historical and artistic patrimony of our towns, and of great complexity because of the specificity of each case.

The whole of those four works intend to reflect some of the most common problems in this dink of project and their correct solution.

The first correspond to a building of three floors with a semibasement that, after being emptied and rebuilt, a new body of four floors is added using completely different methods according to the municipal council ordinances.

The second work includes two buildings of a very different use (an ice factory and its offices) constructed in consecutive periods and with different constructive treatments which obliges to search a diverse solution for each body.

The third project is an action taken by the City Council of Madrid, who acted by substitutive execution considering the high danger of ruin of the building and the passiveness of its owners.

The last work is a house-building on a ground plan shaped as an $L$ with six levels on top of the basement.

\section{CONSERVACION DE LA FACHADA PARA UN APARTOTEL EN LA C/COVARRUBIAS}

\section{Jesús Serra Gesta, Arquitecto}

El edificio de la c/ Covarrubias, n. $8, \mathrm{c} / \mathrm{v}$ a c/ Manuel González Longoria de Madrid, era un edificio de principios del siglo $X X$, sin características especiales o de suficiente calidad que hiciesen recomendable su conservación. Por ello estaba clasificado en el Plan Especial de la Villa de Madrid con Protección Ambiental, susceptible, en consecuencia, de ser demolido y sustituido por una edificación de nueva planta en su totalidad. El edificio presentaba el aspecto de la fotografía de la figura 1.

No obstante el Ayuntamiento de Madrid y la Dirección General de Bellas Artes exigieron el mantenimiento de la fachada existente, autorizando la demolición interior y la construcción de nueva planta de todo el interior y el recrecido sobre el edificio existente con cuatro plantas, obligando a que estas nuevas plantas se cerrasen a base de muro cortina con vidrio reflectante a fin de conseguir el efecto "espejo" de las edificaciones del entorno. El proyecto realizado siguiendo estas directrices presentará, una vez construido, el aspecto que recoge el dibujo de la figura 2 , en que se restaura la fachada antigua y se construyen las cuatro nuevas plantas retranqueando la primera de ellas con el fin de marcar la diferencia entre la fachada antigua y el recrecido.

El nuevo edificio se destina a Apartotel o Residencia de alta categoría.

Constructivamente el edificio existente se había realizado a base de muros de fábrica de ladrillo macizo y viguería de pertiles metálicos I PN formando dos crujías paralelas a fachada, no existiendo en consecuen- 


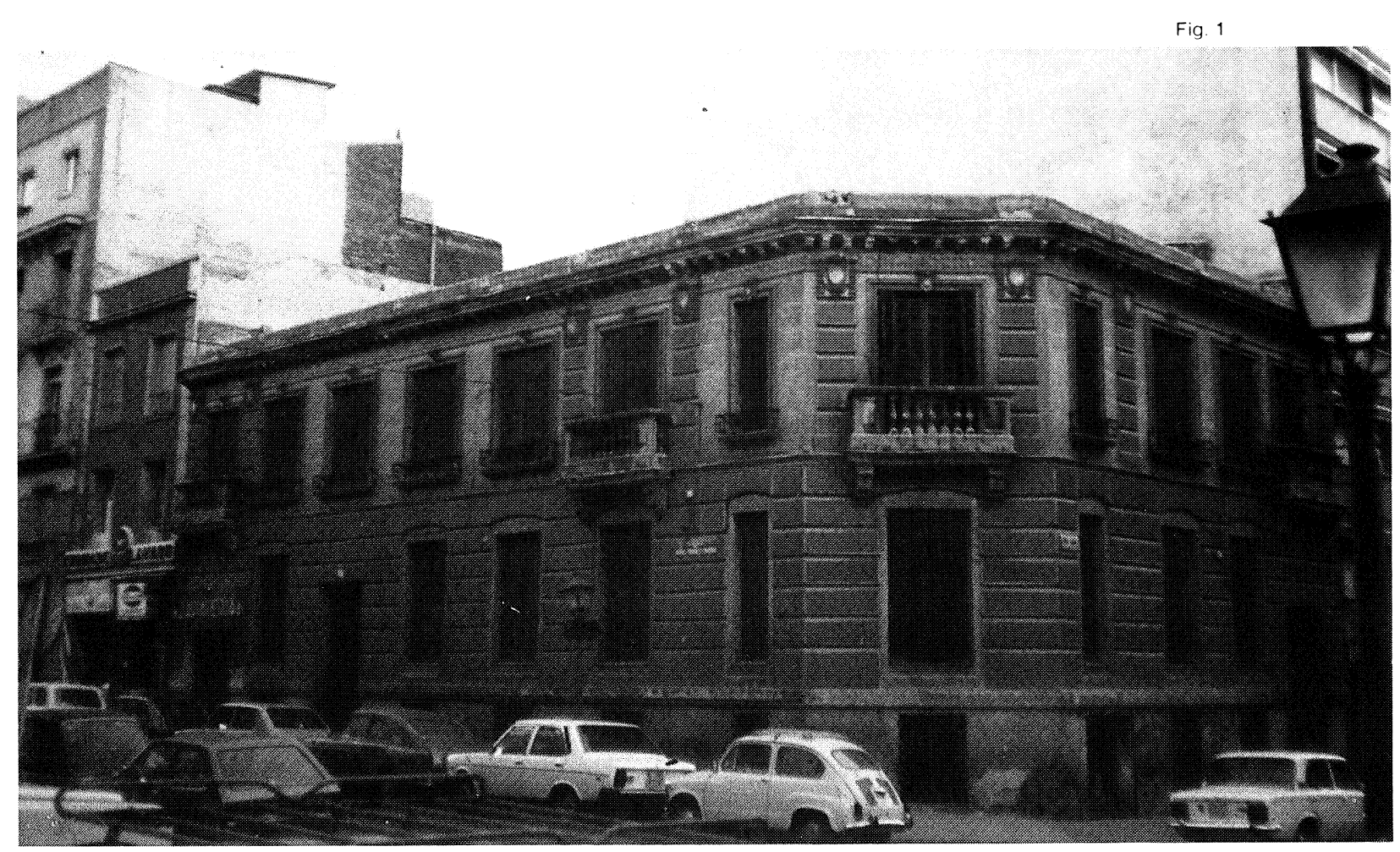

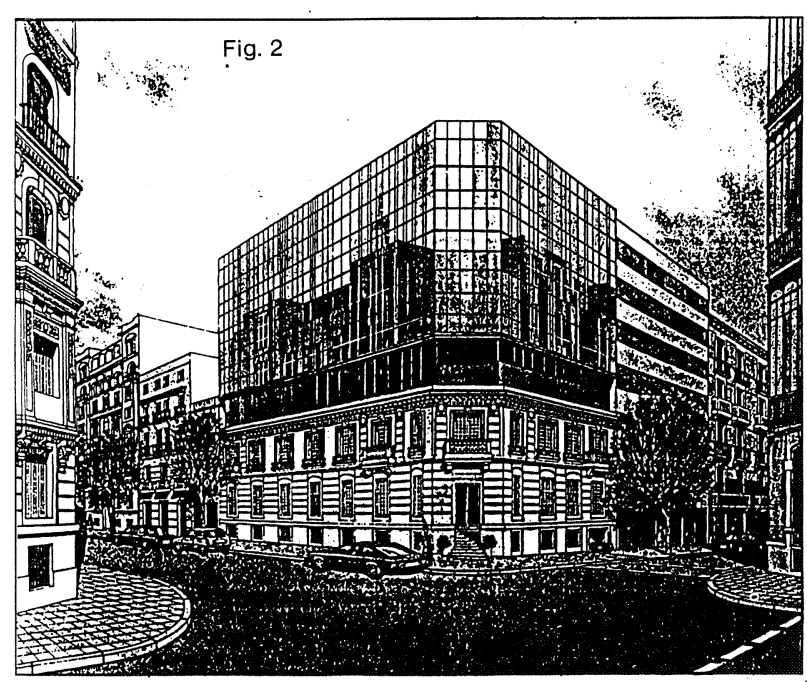

cia muros transversales. Los adornos, cornisas, balaustres, etc., son de escayola o piedra artificial sin demasiada calidad.

Al planificar la ejecución de la obra se planteaban dos problemas principales derivados ambos de la necesidad de mantener la fachada.

El primero era que al demoler el interior, cortando en consecuencia los forjados, todo el muro de fachada quedaba totalmente suelto sin arriostramiento transversal con el consiguiente riesgo de vuelco del mismo. El segundo problema que se planteaba era que al rebajar el nivel del semisótano existente, el plano de apoyo del muro en el terreno quedaba descolgado. Es de destacar que los muros de fábrica no tenían cimentación alguna apoyando los mismos directamente sobre el terreno.
El problema de estabilidad al vuelco de la fachada, se resolvió arriostrando la misma por medio de andamiaje tubular, atando la fábrica a través de los huecos de ventanas y balcones, y lastrando el mismo por medio de cajones de grava con un peso de $2.000 \mathrm{~kg} / \mathrm{m} . \mathrm{l}$.

En las figuras 3 a 5 se muestra el esquema del andamiaje que fue realizado por la casa "IN" y en las fotografías de las figuras 6 a 8 el adamiaje colocado tanto desde el exterior como desde el interior vaciado (no se aprecian los cajones de lastrado al quedar tapados por la valla de obra).

El otro problema consistió, como se ha dicho, en recalzar todo el muro de fachada al quedar descolgado el plano de apoyo como consecuencia de rebajar el nivel del semisótano, más la excavación necesaria para construir la cimentación de la nueva estructura que era por medio de losa de cimentación de $70 \mathrm{~cm}$ de canto.

El recalce se ejecutó por medio de bataches transversales al muro, con anchos variables no superiores a $1,50 \mathrm{~m}$, siguiéndose la siguiente secuencia:

1) Excavación del batache dejando en los laterales bermas del terreno sin excavar; 2) Excavación bajo el muro en la profundidad necesaria; 3 ) Encofrado de la zona excavada con igual ancho que el muro existente; 4) Hormigonado del recalce dejando sin hormigonar los últimos 25 a $35 \mathrm{~cm}$; 5) Una vez fraguado el hormigón y tenido lugar la consiguiente retracción del mis mo, retacado a base de fábrica de ladrillo para garantizar la adecuada puesta en carga de la misma sin dar lugar a asientos o deformaciones que pudiesen agrietar el muro. 

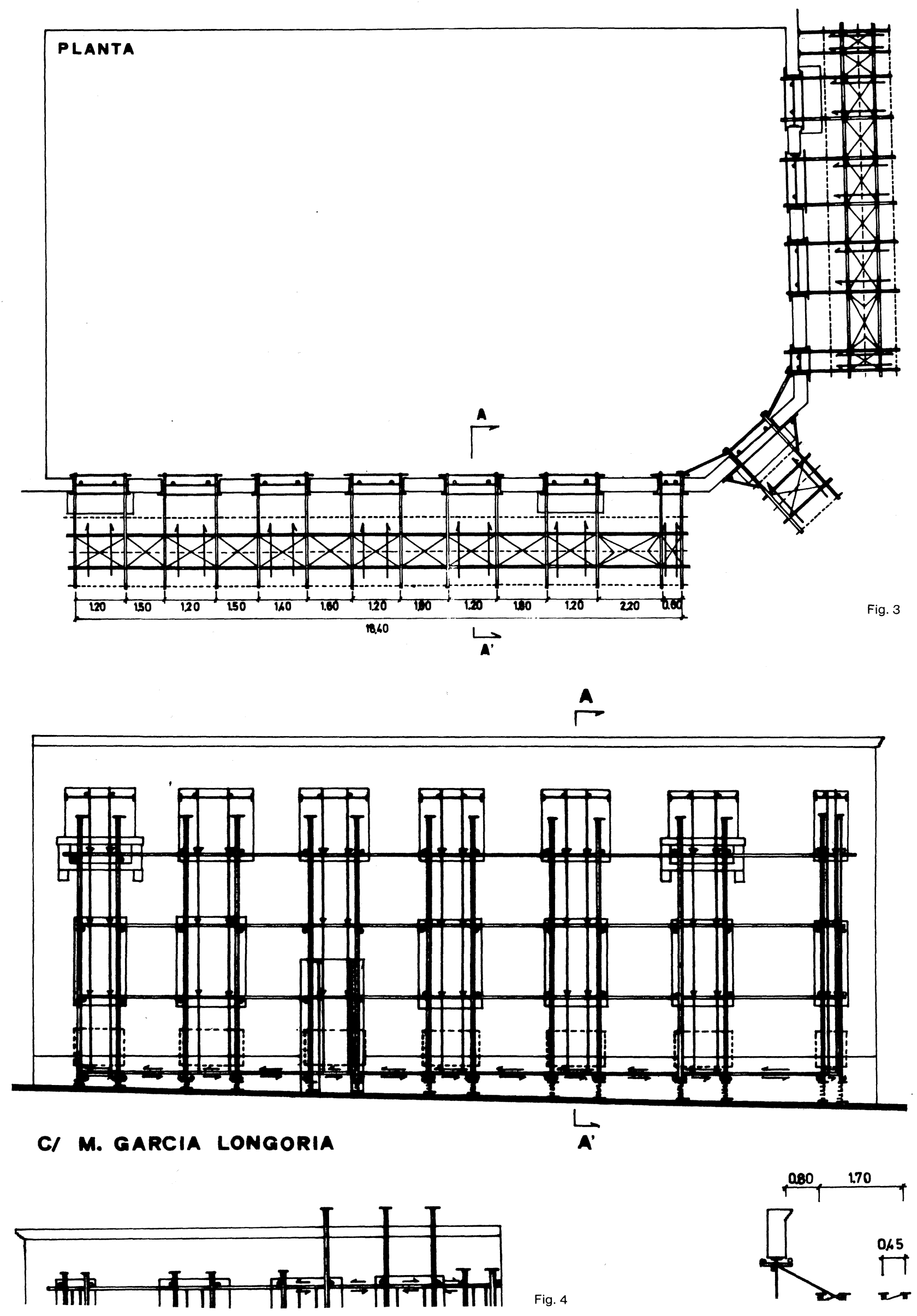

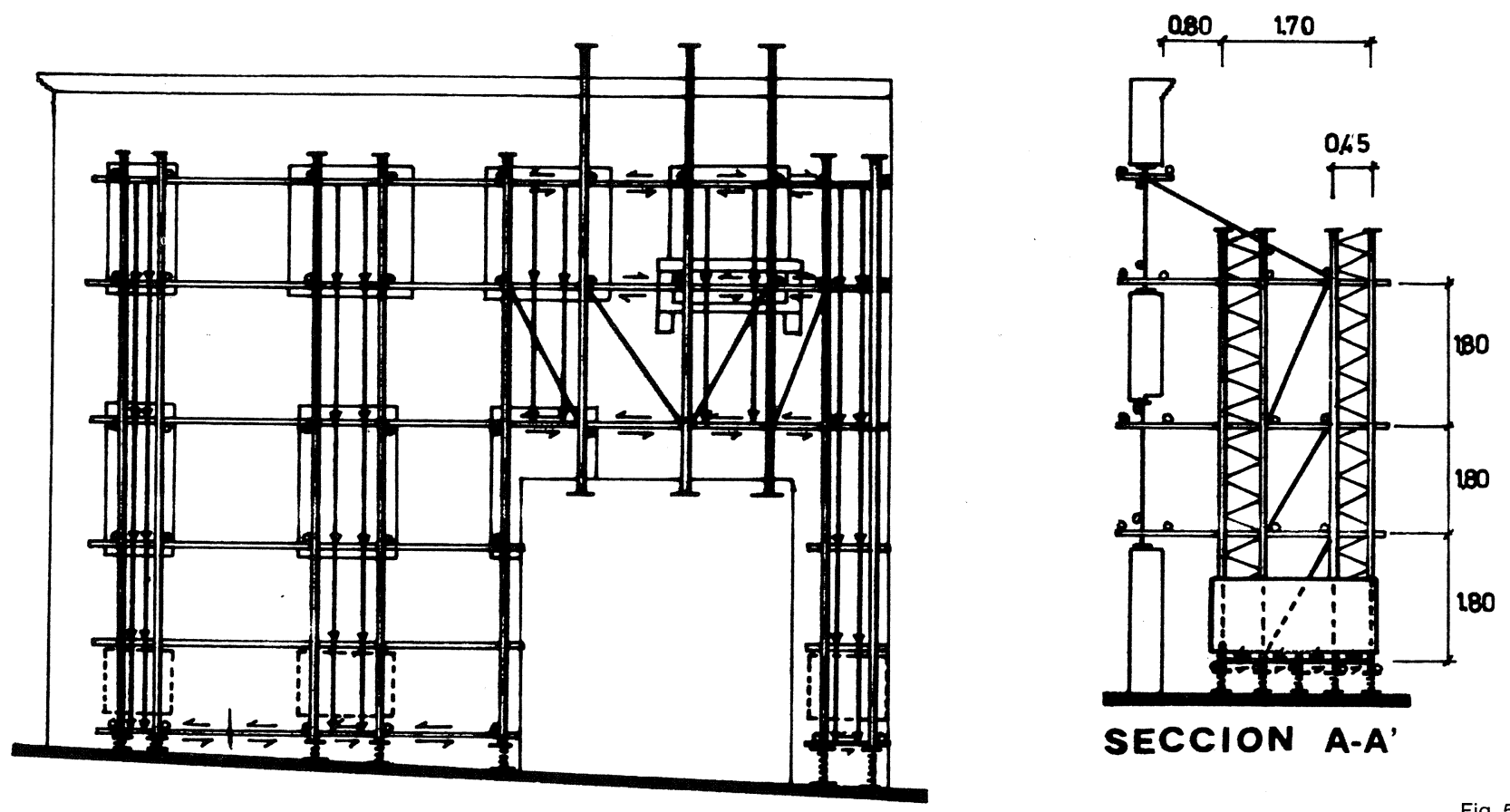

C/ COVARRUBIAS
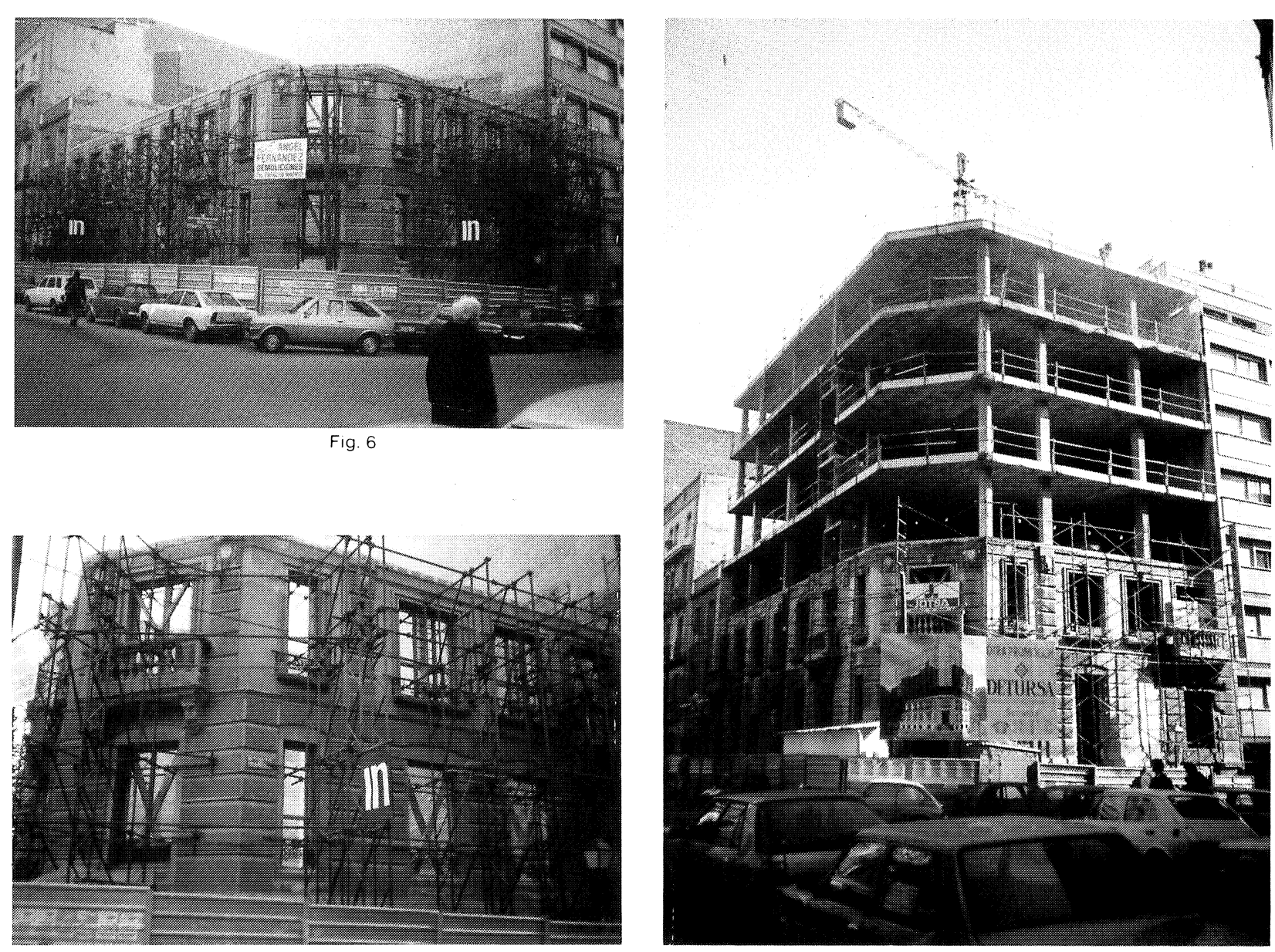

Fig. 7

Fig. 9 


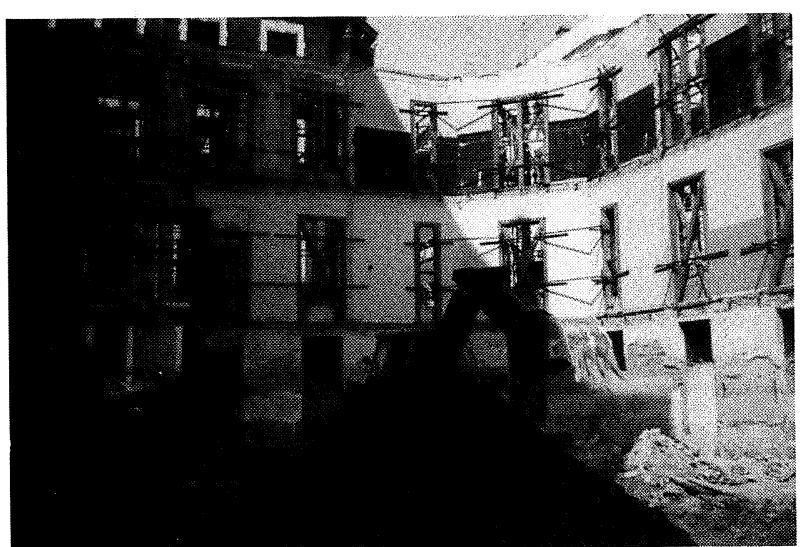

Fig. 8

Resueltos estos problemas, la ejecución de la obra no presentó más peculiaridades que cualquier obra de nueva planta, con la excepción de que al construir los nuevos forjados hubo que cuidar el atado de los mismos al muro existente.

El edificio en el momento actual presenta el aspecto de la figura 9. La estructura se encuentra terminada y se está procediendo a la colocación del muro cortina y a la restauración de la fachada antigua, adaptando algunos huecos a las necesidades del futuro uso del nuevo edificio.

\& 8 is

CONSERVACION DE LAS FACHADAS DE UNA ANTIGUA FABRICA DE HIELO EN LA C/LA PALMA

\section{Manuel Peña Arribas y Braulio Peña Arribas, Arquitectos}

El edificio se encuentra en un solar de $1.056 \mathrm{~m}^{2}$, situado en el barrio de Malasaña, de Madrid, en la calle de la Palma, c/v a la calle de San Andrés. Afectado por el Plan Especial Villa de Madrid, se debían conservar las fachadas existentes en su estado actual, restaurándolas a su primitivo estado, motivo por el que el planteamiento ejecutivo de las obras quedó condicionado a la conservación de estos elementos que configuran la trama urbana.

Sobre el solar existían dos edificaciones construidas en diferentes etapas a principios de siglo. En ambas se albergaban usos complementarios, siendo de oficinas el de la calle de la Palma y de fabricación de hielo el de la calle de San Andrés. Ambos poseen fachadas resueltas de diferentes maneras, teniendo el primero unas características acordes con el entorno urbano, mientras el segundo, con acabado de ladrillo de tejar a cara vista, va manifestando la cobertura interior en cu- chillos según acometían las crujías interiores, con huecos rematados en arcos de medio punto.

La nueva edificación se resuelve vaciando el interior del solar y manteniendo las fachadas actualmente existentes, retraqueándolas en la parte de la fachada de la fábrica y acometiéndolas en el resto, constituyendo esta unión una junta de dilatación coincidente con la división de los dos cuerpos de fachada.

El edificio se compone, verticalmente, de dos sótanos y cuatro plantas sobre rasante.

Con anterioridad a la demolición del interior, se proyectó el apeo de las fachadas mediante una estructura capaz de absorber los posibles esfuerzos horizontales que se pudieran ocasionar. Dicha estructura está compuesta por elementos tubulares que, mediante tubos introducidos por los huecos de fachadas y cruzados transversalmente por otros, tanto en el interior

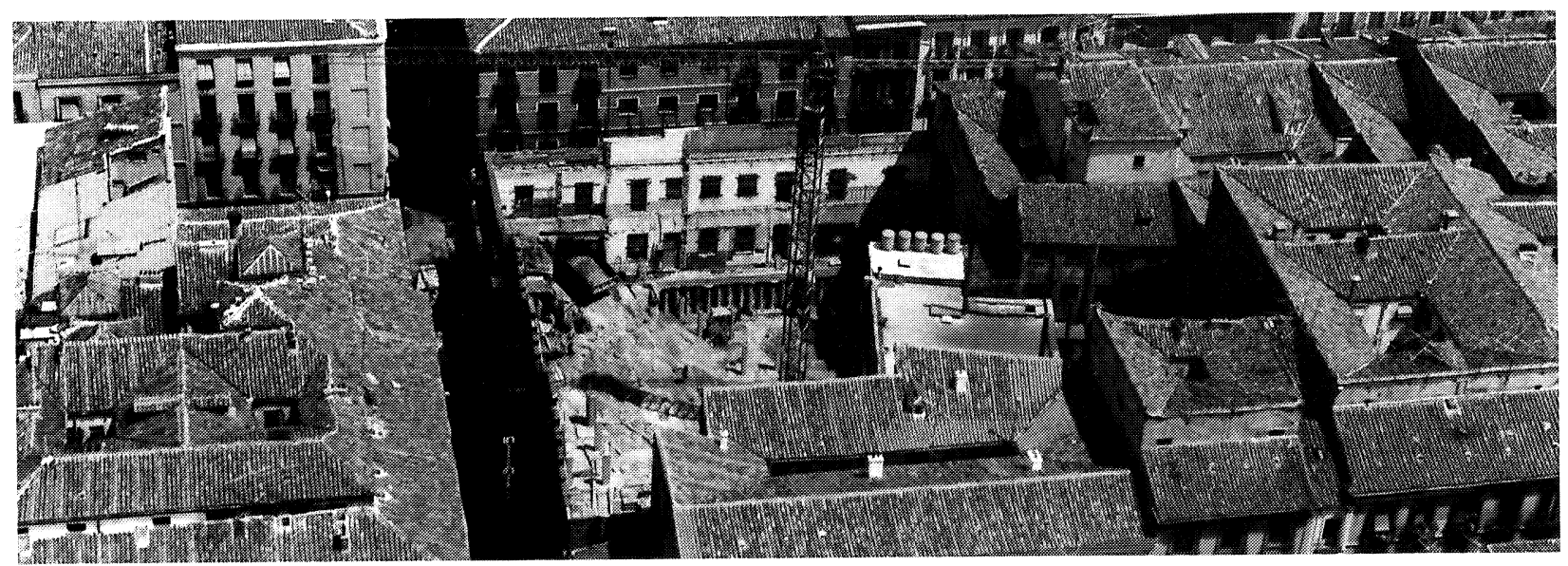


como en el exterior y a la altura del dintel y del antepecho, abrazan el muro, disponiendo un lastre en su base que absorbe los momentos producidos por dichos esfuerzos. En los paños ciegos de grandes dimensiones se realizaron perforaciones para poder sujetar el muro de la misma forma.

El vaciado del solar para los sótanos se efectuó previa ejecución de la pantalla de contención de tierras, formada por pilotes discontinuos. Para este pilotaje, se emplearon pilotes in situ, con perforación rotacional. De esta manera se evitaban vibraciones y movimientos bruscos junto a fachadas y medianerías, que hubieran podido ocasionar cualquier tipo de fisuración. Los pilotes van unidos en cabeza por una viga de atado, en la cual, y hacia el exterior a modo de ménsulas, se realizan las cimentaciones de los soportes de la estructura metálica.

La línea de ejecución del muro se tuvo que retranquear de las fachadas con el fin de seguir manteniendo un apoyo horizontal.

La estructura del nuevo edificio se resuelve con forjado bidireccional y soportes de hormigón armado. Esta estructura se completa con otra metálica embutida y grapada en fachada.

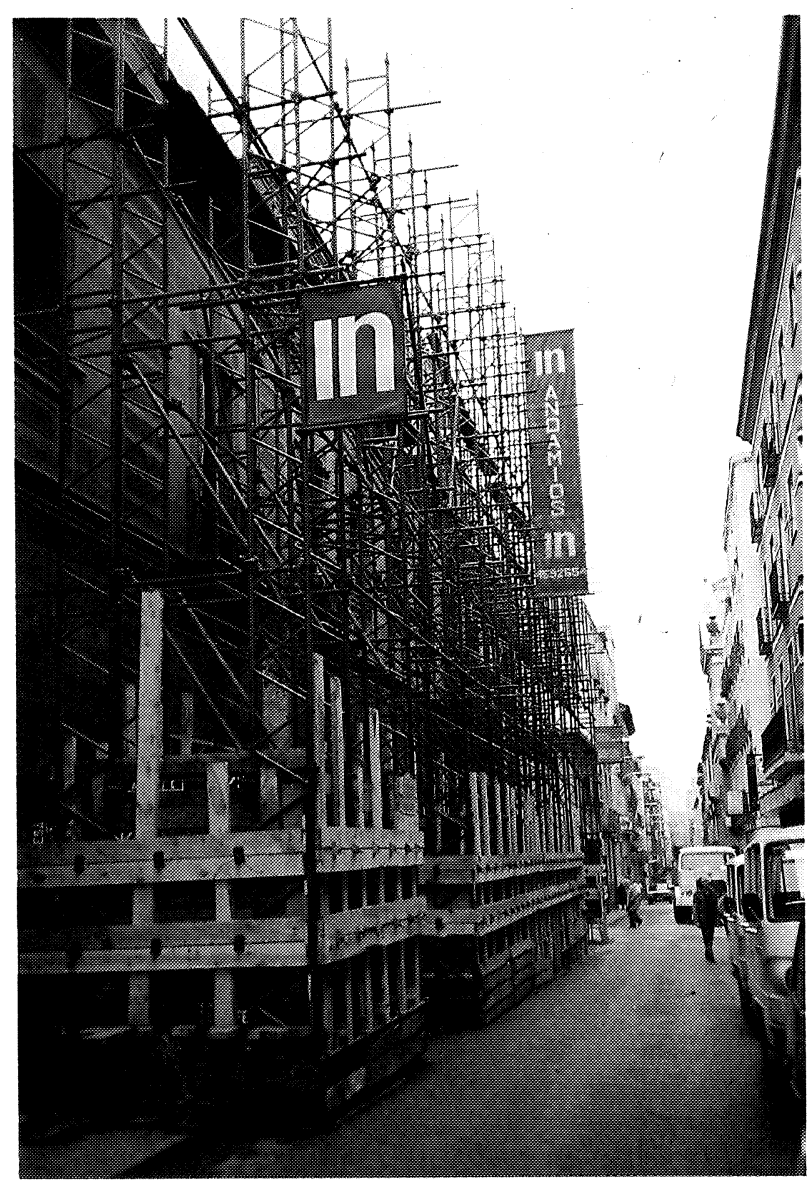

Calle de La Palma
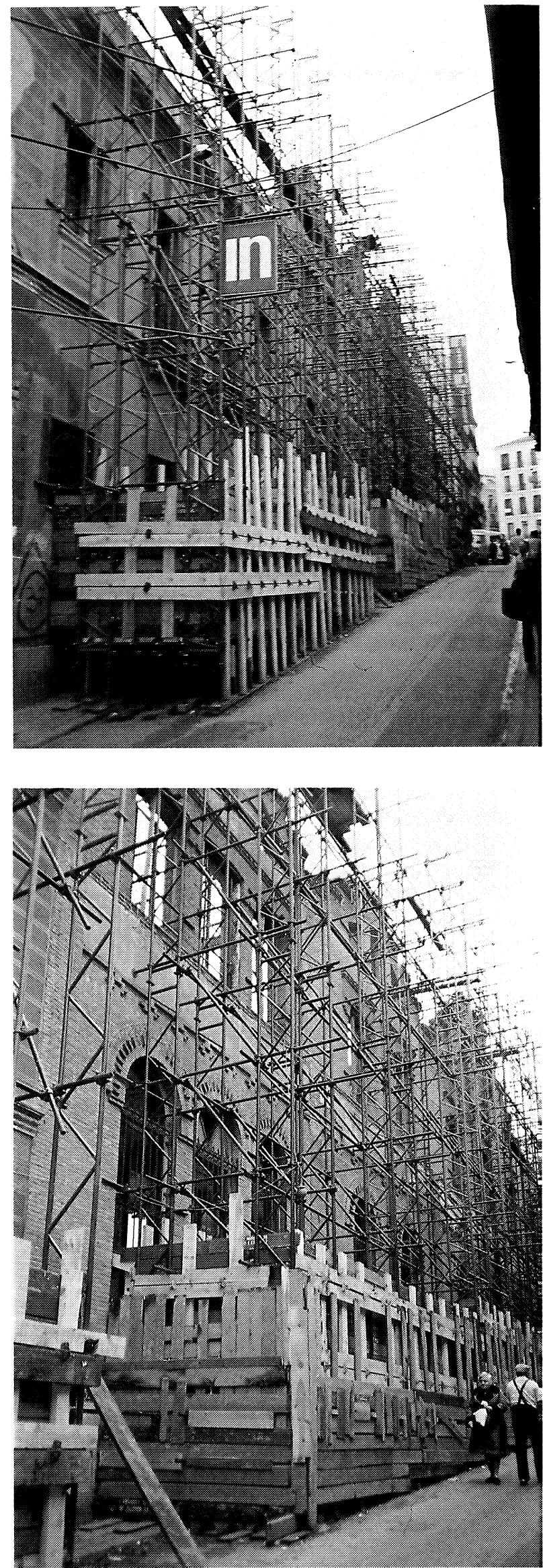

Calle de San Andrés 


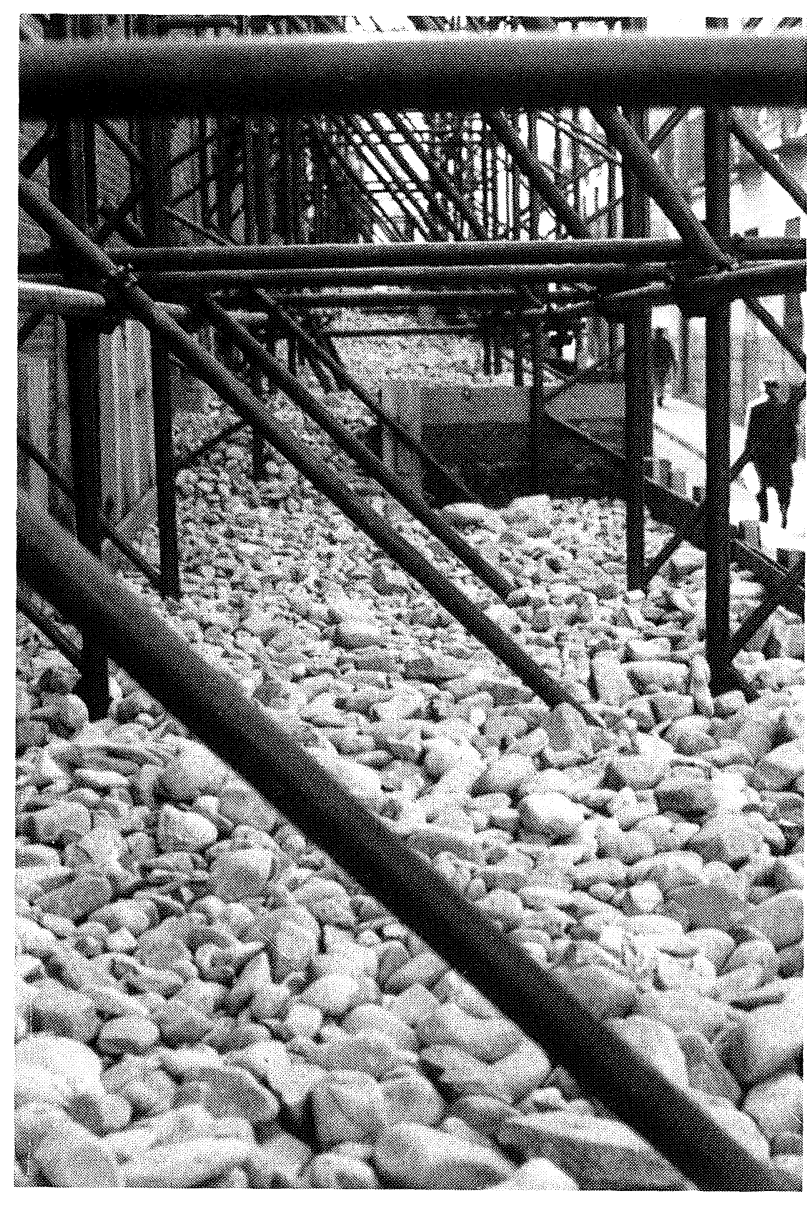

En el cuerpo de la calle de la Palma, la estructura metálica cumple dos funciones: la primera como elemento de sujección de la fachada, y la segunda como parte portante del edificio. Así, se han dispuesto pilares metálicos que, embebidos en el muro de fachada y grapados en varios puntos de sujeción, actúan como elemen- tos sustentantes de los esfuerzos horizontales de la fachada, siendo, a su vez, soportes extremos de los pórticos del nuevo edificio, que aligeran las cargas que se pudieran transmitir a los muros de fachada. Como elementos horizontales se disponen zunchos de hormigón y metálicos, que sustentan los forjados que acometen a fachada o al patio de luces. Los forjados se proyectan conservando las alturas primitivas de las fachadas, y dado que éstas están provistas de resaltos, por la disminución de la sección del muro según se va elevando con respecto al nivel de la calle, se aprovechan dichos resaltos para realizar los zunchos, tanto de hormigón como metálicos, guardando así similar distribución de cargas que las que poseía anteriormente.

En el cuerpo de la calle de San Andrés, el problema es distinto. La fachada es muy esbelta y tiene mayor proporción de huecos, por lo que la estructura metálica no se llega a embutir por entero. El diseño de la estructura se realiza teniendo en cuenta la distribución de cargas que tenía previamente a la demolición del edificio, si bien, debido a sus propias características, se evita en todo momento la transmisión de esfuerzos. Dicha estructura se conforma siguiendo una línea en forma de cuchillos, en donde apoyaban las correas de la cubierta del edificio antiguo. Se completa dicha línea con un entramado de elementos horizontales y verticales capaz de absorber los posibles esfuerzos horizontales. Estos esfuerzos condicionaron el diseño de la unión de la estructura metálica con la de hormigón armado, y así, para evitar alguna posible transmisión de esfuerzos de la estructura de hormigón a la metálica de fachada, se dispone una viga metálica doblemente articulada, por un lado con la estructura de fachada, y por el otro en la unión con las ménsulas de hormigón del nuevo edificio. De esta manera las posibles deformaciones de estos elementos no transmitirán esfuerzos a las fachadas.

$$
\text { \& \& \& }
$$

\section{Santiago González Rodríguez y Fernando Macías Hidalgo-Saavedra,}

Arquitectos

(Gerencia Municipal de Urbanismo)

Esta obra, realizada por el Ayuntamiento de Madrid por ejecución sustitutoria, presentaba graves daños que se acusaban principalmente en los desniveles de los forjados de pisos y en el desplome de la fachada a la plaza de San Martín, cuyo desplazamiento máximo estaba a nivel del forjado de la planta segunda, donde cambiaba de signo produciéndose un quiebro.

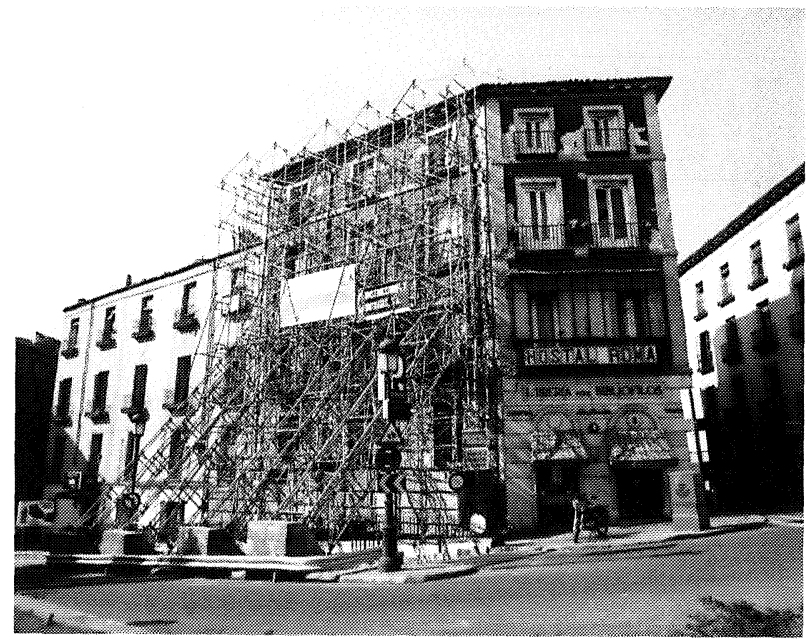


Asimismo las grietas y desconchones del revoco, la descomposición de la fábrica de ladrillo y el desprendimiento de impostas y recercado de huecos, eran cada vez más notorios debido a las humedades provocadas por el mal estado de las bajantes de pluviales y de las repisas de balcones.

Era patente el riesgo de hundimiento que supondría un nuevo incremento del desplome del muro de fachada, aparte de los desprendimientos del revoco y de los elementos decorativos, que podían causar accidentes en la vía pública dado que la acera está limitada por el pretil y barandilla de la rampa de acceso al aparcamiento de la Plaza de las Descalzas, sin posible huida hacia el exterior.

Ante la gravedad de la situación se propusieron como medidas urgentes, además de cortar el paso por la acera, apuntalar el muro de fachada y el apeo de los forjados de piso en una línea paralela a la fachada, en todas las plantas.

Para el apuntalamiento exterior se eligió el sistema de tornapuntas de estructura tubular, formado por tubos comerciales de diámetros $60 \times 3 ; 50 \times 3$ y $35 \times 2 \mathrm{~mm}$.

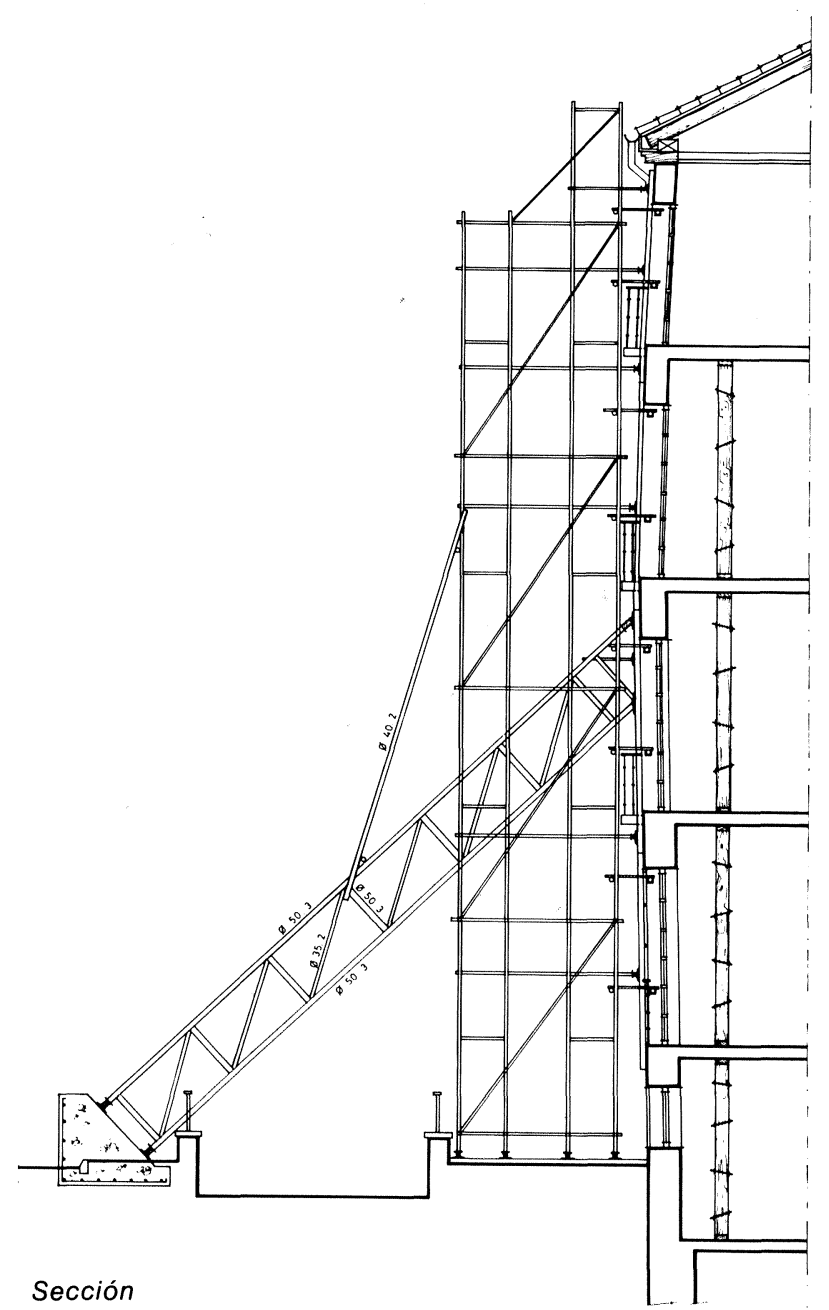

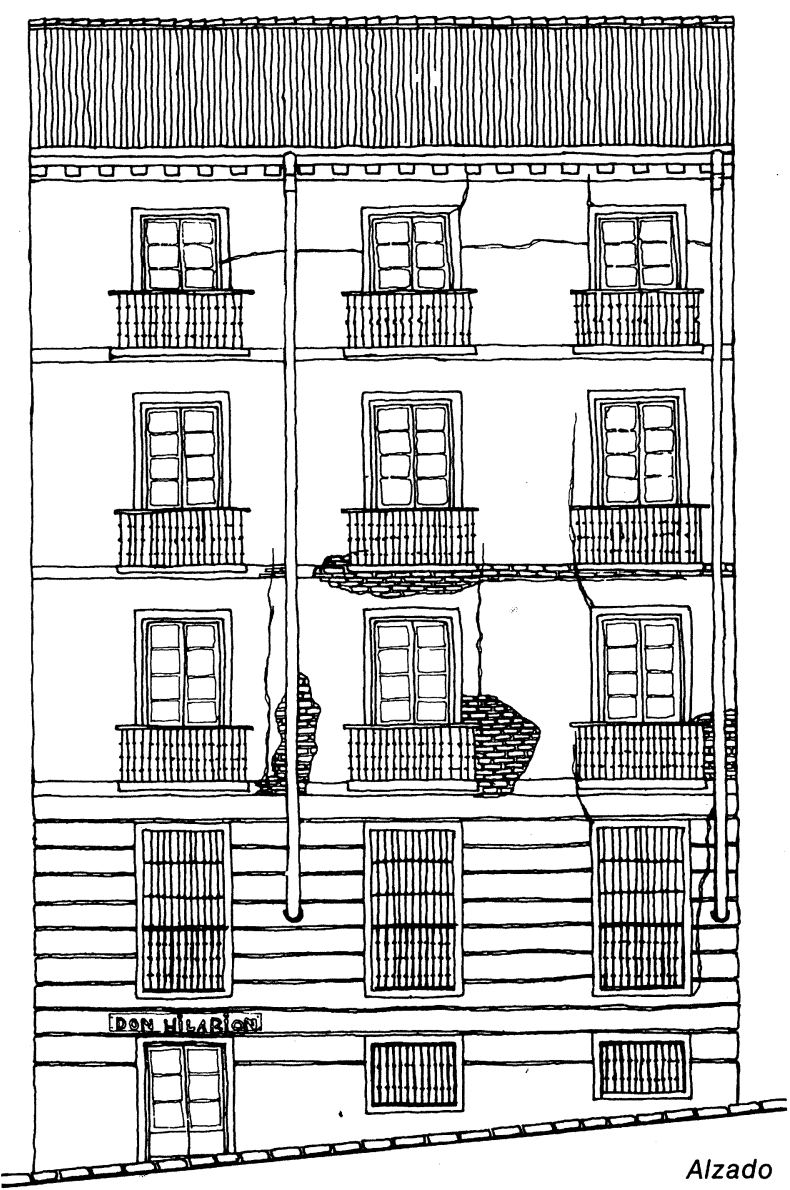

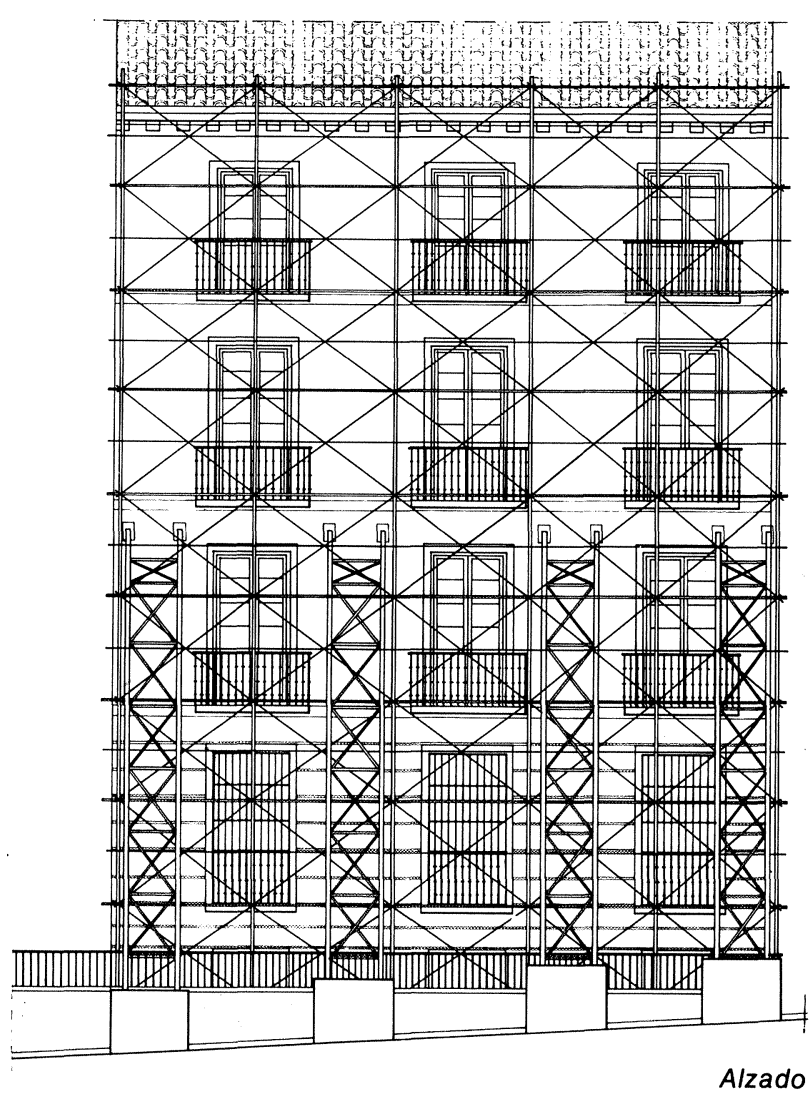



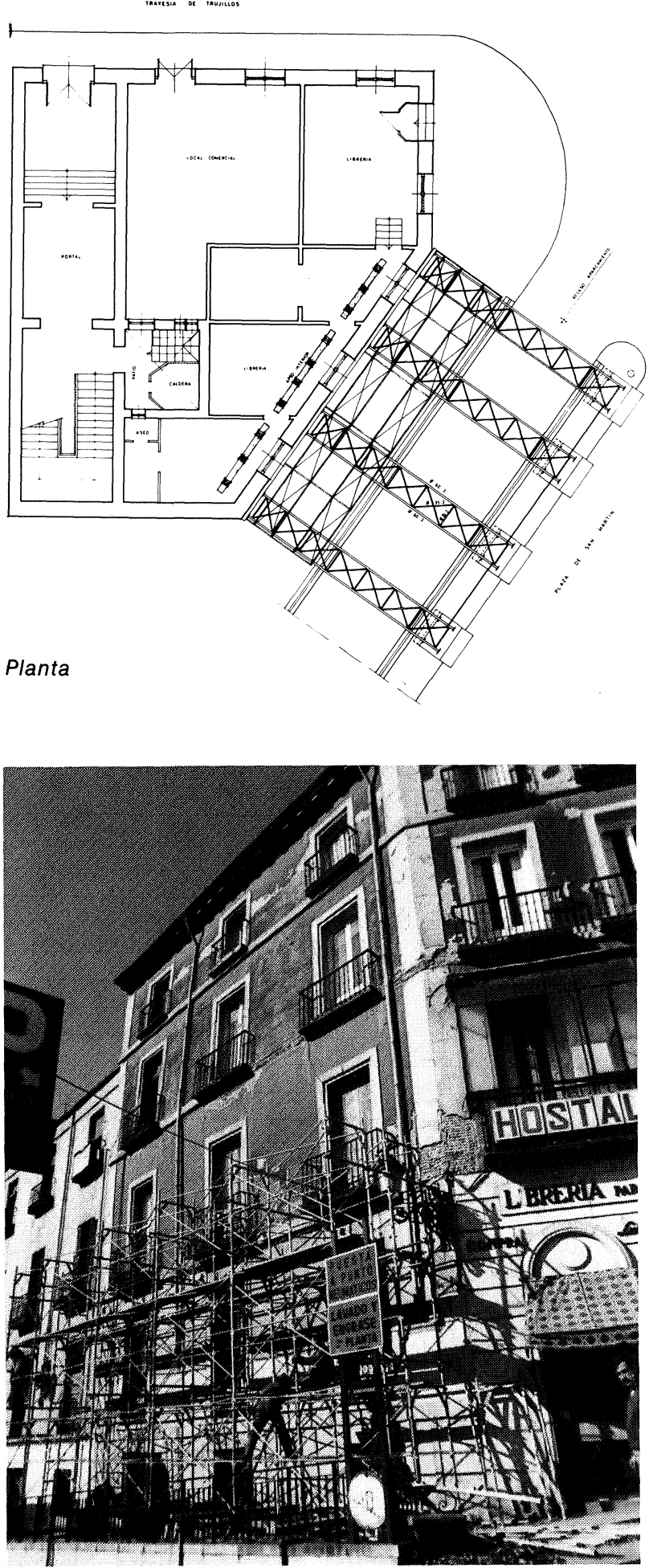

Se dispusieron cuatro torretas hasta la altura de la segunda planta, interponiendo tablones de reparto sobre el muro. En la base se anclan sobre unos dados de hormigón realizados sobre la calzada, sin excavar más que la capa de asfalto y el picado necesario para conseguir una buena adherencia sin dañar la impermeabilización del aparcamiento. Dichos dados cargan en parte sobre el muro de contención de la rampa de acceso al aparcamiento y en parte sobre la losa de hormigón, sin afectar directamente a ésta.

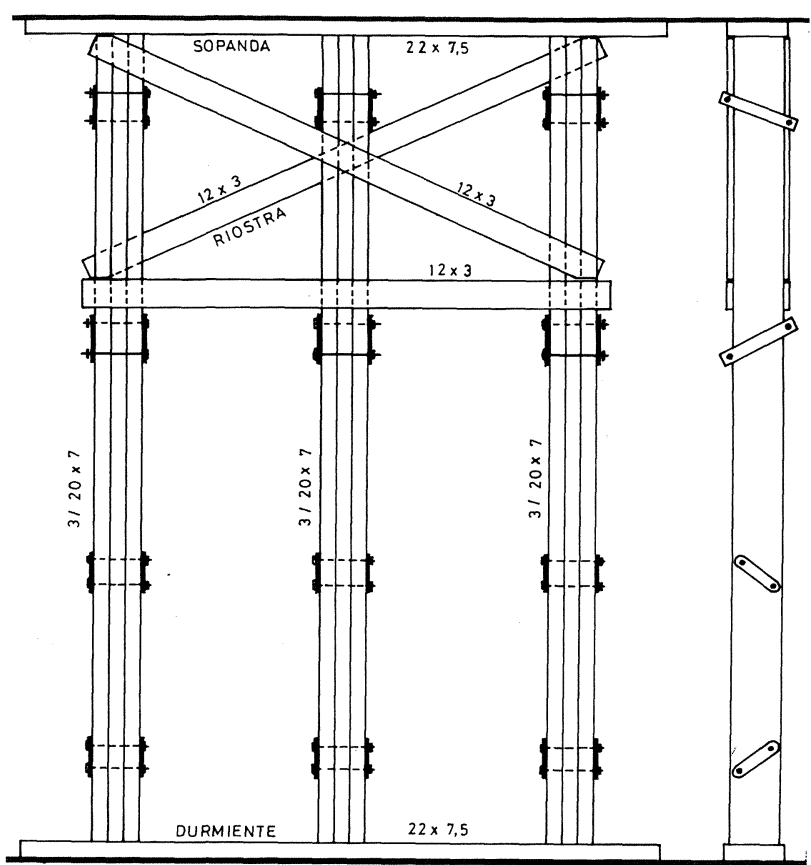

Detalle apeo interior

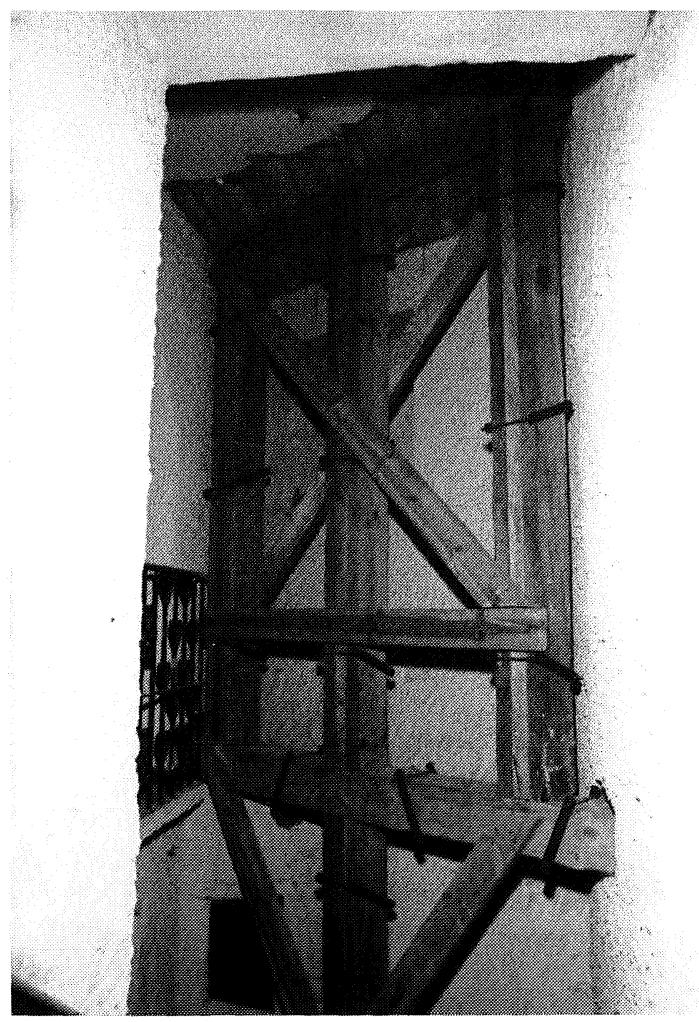

La carga trasmitida al suelo por cada tornapuntas es de 12,96 toneladas, que sumada al peso propio de la estructura $-1,00 \mathrm{t}-\mathrm{y}$ de la zapata $-8,53 \mathrm{t}-$, da un total de 22,53 toneladas. En conjunto la carga de los cuatro tornapuntas se reparten sobre una superficie de $15 \times 1,5 \mathrm{~m}^{2}$, lo que equivale a una presión de $0,4 \mathrm{~kg} / \mathrm{cm}^{2}$. 


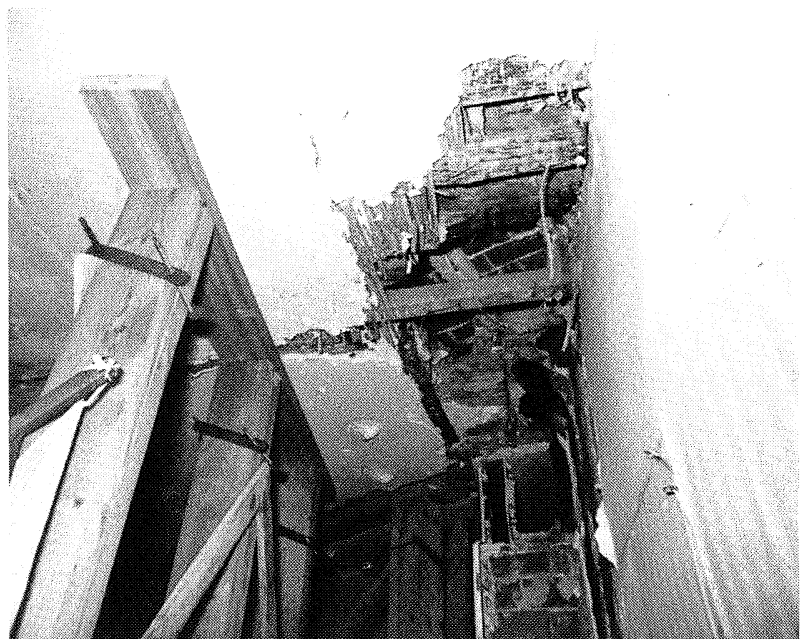

El aprieto para la puesta en carga se hace mediante husillos en la base, que reparte la carga sobre el dado de hormigón a través de unas placas de acero.
Asimismo se dispone un andamiaje complementario que sirve de arriostramiento y facilita el montaje, llegando hasta la línea de cornisa, que servirá en su día para efectuar las obras de reparación.

El apeo interior se realizó con pies derechos formados portres tablones de $20 \times 7 \mathrm{~cm}$, embridados, dispuestos sobre durmientes de $22 \times 7,5 \mathrm{~cm}$, y repartiendo sobre los techos con sopandas de la misma escuadría. Con el fin de dejar el paso libre entre elos, el arriostramiento se hizo en la parte alta con tabloncillo de $12 \times 3 \mathrm{~cm}$.

El apeo se comenzó por el sótano para terminar en la planta segunda, templando las cuñas convenientemente. Entre el paramento interior del muro de fachada y el apeo se dejó un espacio de 0,60 m para poder circulary trabajar por el interior.

Simultáneamente al apuntalamiento y a la colocación del apeo, se sanearon las partes del revoco, impostas y repisas de balcones que amenazaban desprendimiento o caída a la vía pública.

\section{Blas E. Gómez Infante y \\ Antonio Gómez Infante, Arquitectos}

El edificio objeto del presente Proyecto fue construido posiblemente hacia 1890 . Se trata de una pieza característica de la época (en la semiesquina Norte de la manzana existe otro de una tipología exactamente igual) propia de la construcción del Ensanche que proyectó el Marqués de Salamanca, presentando un aspecto sobrio y sencillo, con una disposición de huecos y alturas propias de aquella época que presentan unos indudables valores ambientales.

Consta de una planta en forma de «L» que se apoya en las calles de Claudio Coello y Hermosilla, y deja en su interior un patio que completa el solar rectangular en que se halla inscrito.

En sentido vertical está compuesto por planta sótano (en ocupación parcial), baja, cuatro plantas de vivienda y una quinta bajo cubierta. En el interior del patio hay construido un pabellón en semisótano con entreplanta, que estuvo destinado a vivienda de portero.

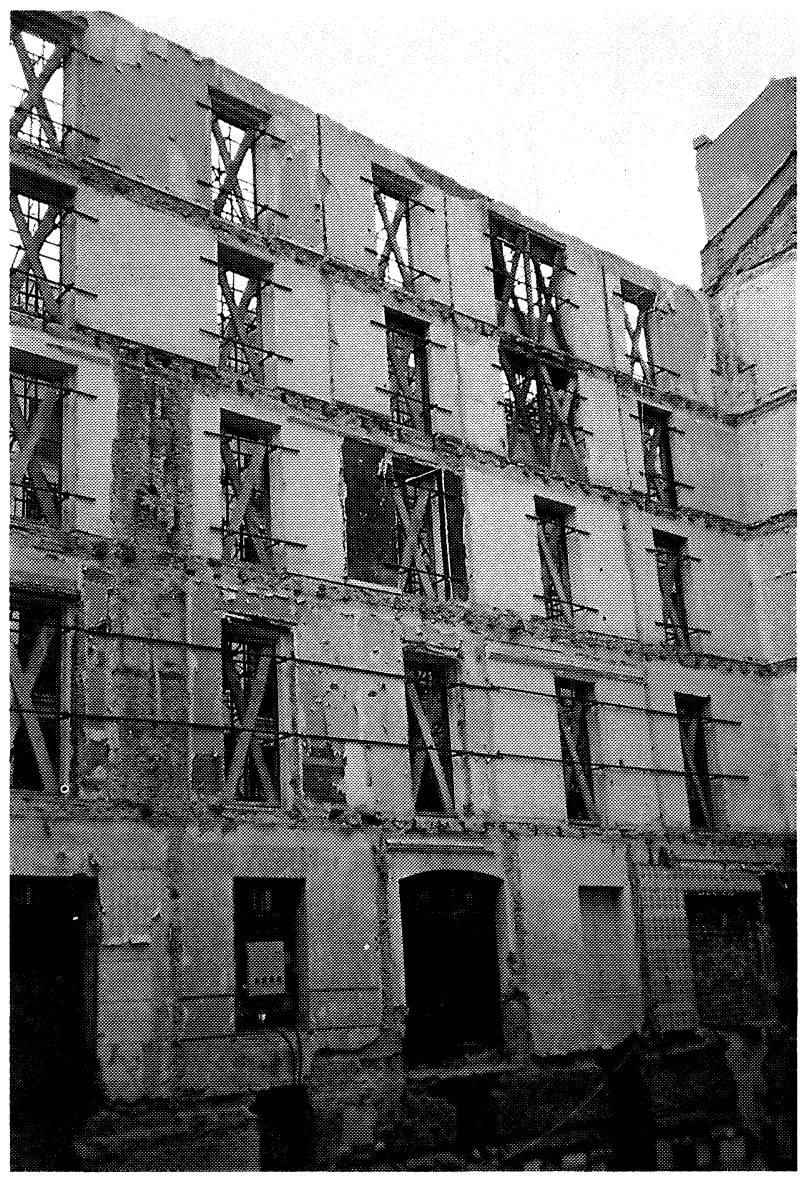



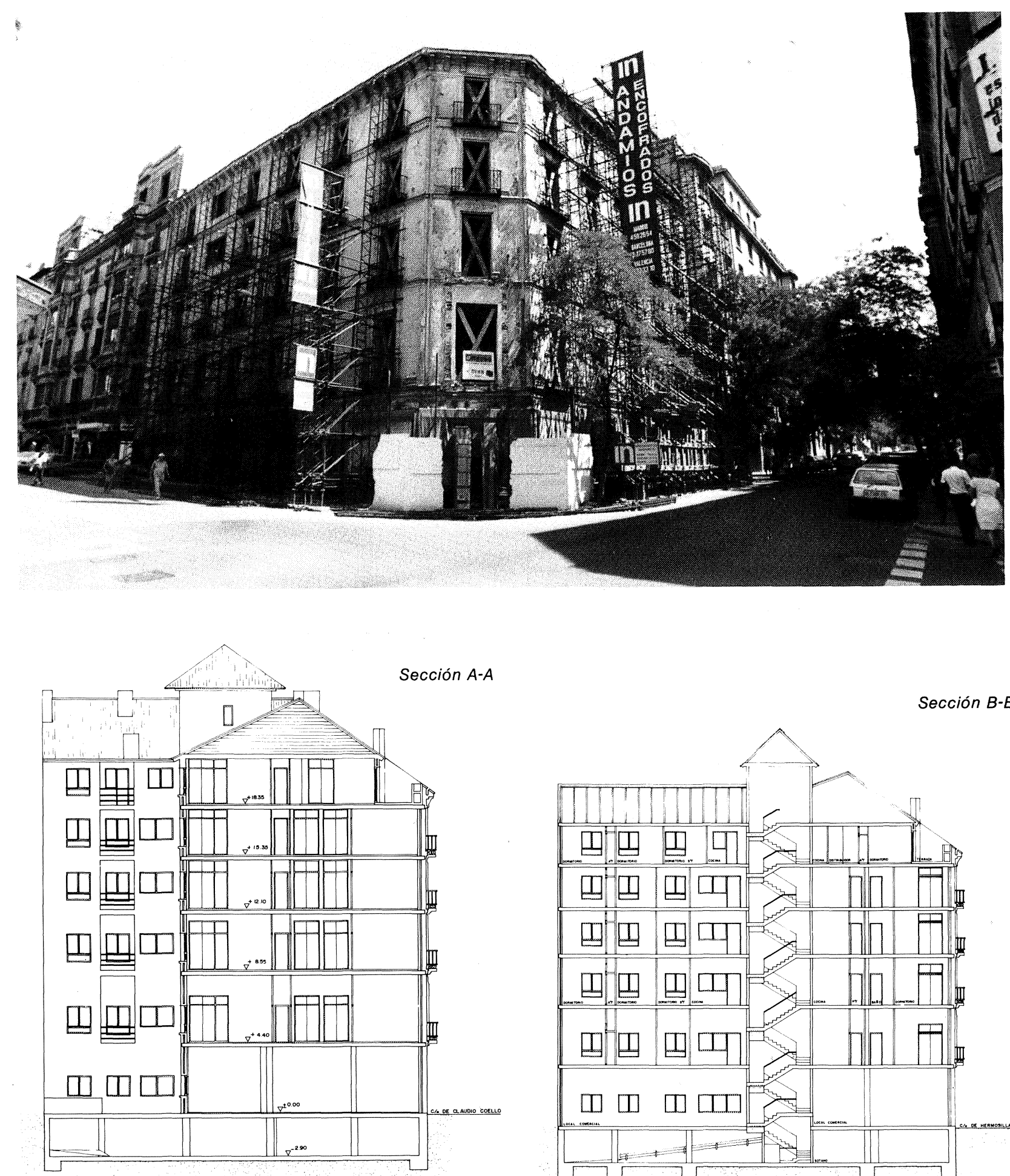

Sección $B-B$

La composición de la fachada presenta una ordenación de huecos en forma, tamaño y disposición uniforme, compuestos por balconeras de dos hojas con fraileros exteriores de venecianas y antepechos de balaustres en hierro forjado. En el chaflán, que se forma en el ángulo de las dos calles, aparece un cuerpo volado en forma de mirador construido, en fábrica, en época más reciente. Todas las ventanas tienen las jambas resaltadas al exterior en forma de refuerzos verticales, coronados en

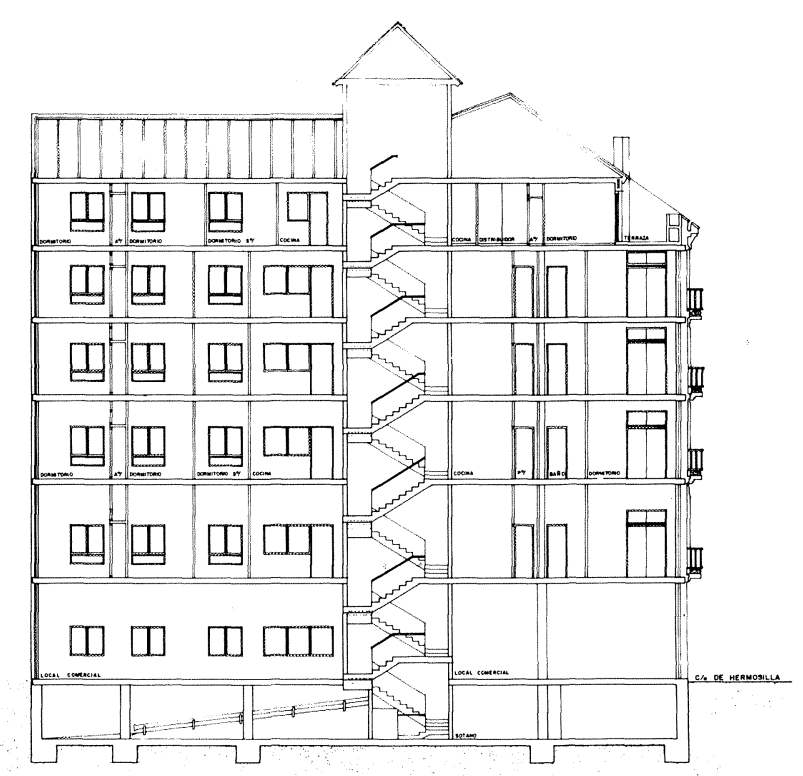

el dintel, por un frontón moldurado y ornamentado. En cada planta discurre horizontalmente y a nivel, en los forjados, una cenefa de bajorrelieve y molduras, con temas de guirnaldas y ramilletes.

Como coronación superior Łapoyo del arranque de cubierta aparece una cornisa a modo de alero, sustentado por canecillos y modillones moldurados. 

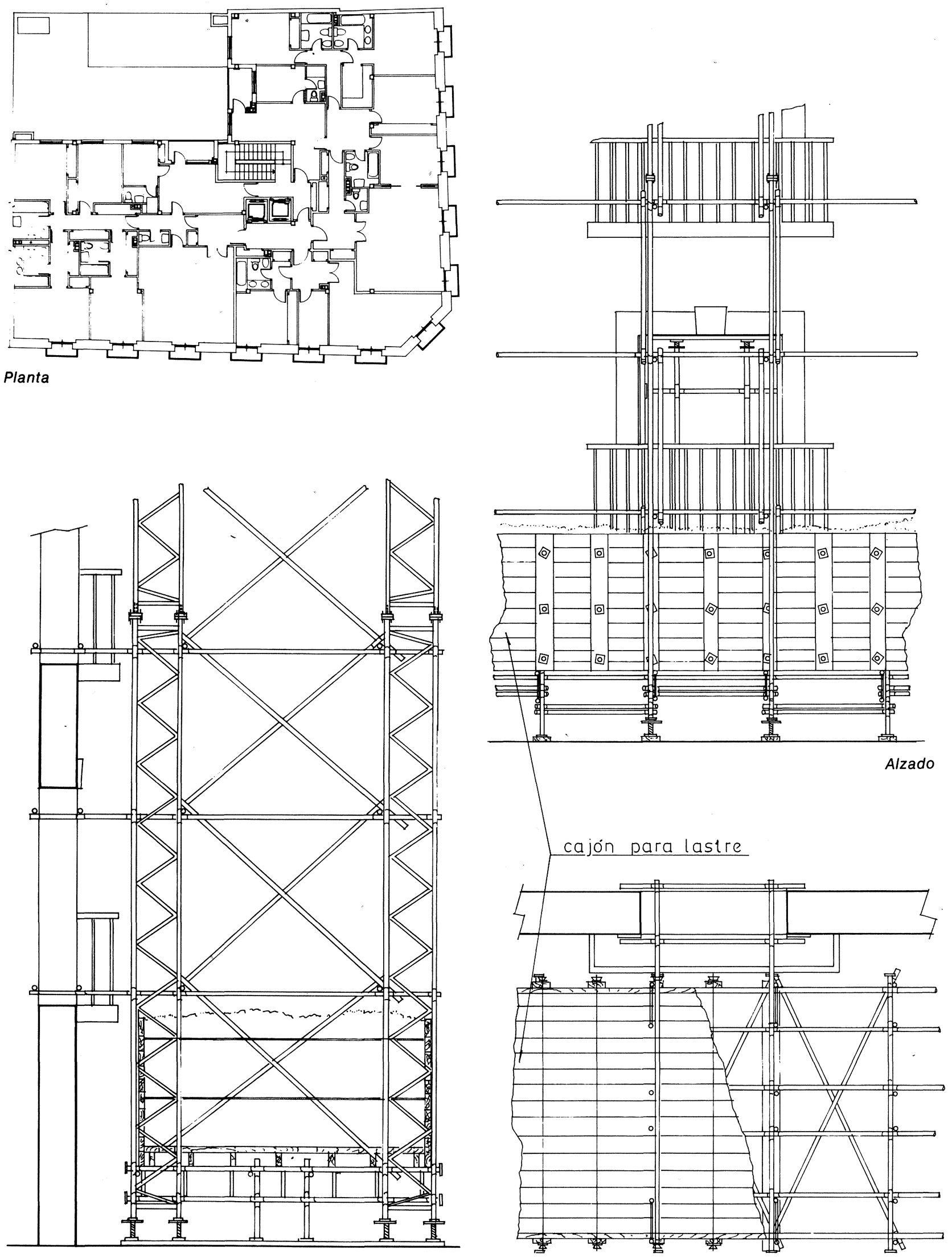

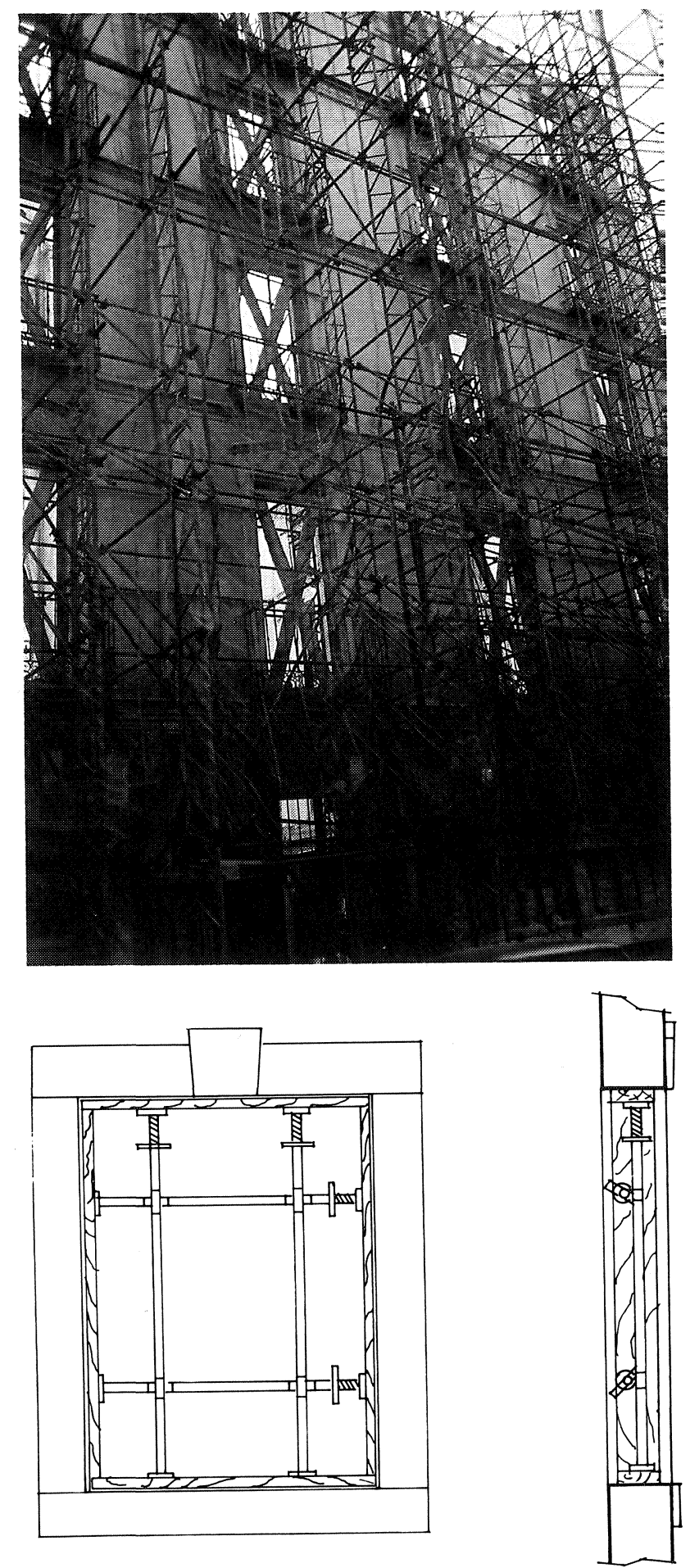

Detalle entibación de huecos

Todos los elementos antes citados están construidos en estuco sobre el soporte de ladrillo que integra la fachada, y sobre los parecillos de madera integrantes de la cubierta.

La superficie ocupada por la planta sótano se extiende a la primera crujía de la fachada exterior.

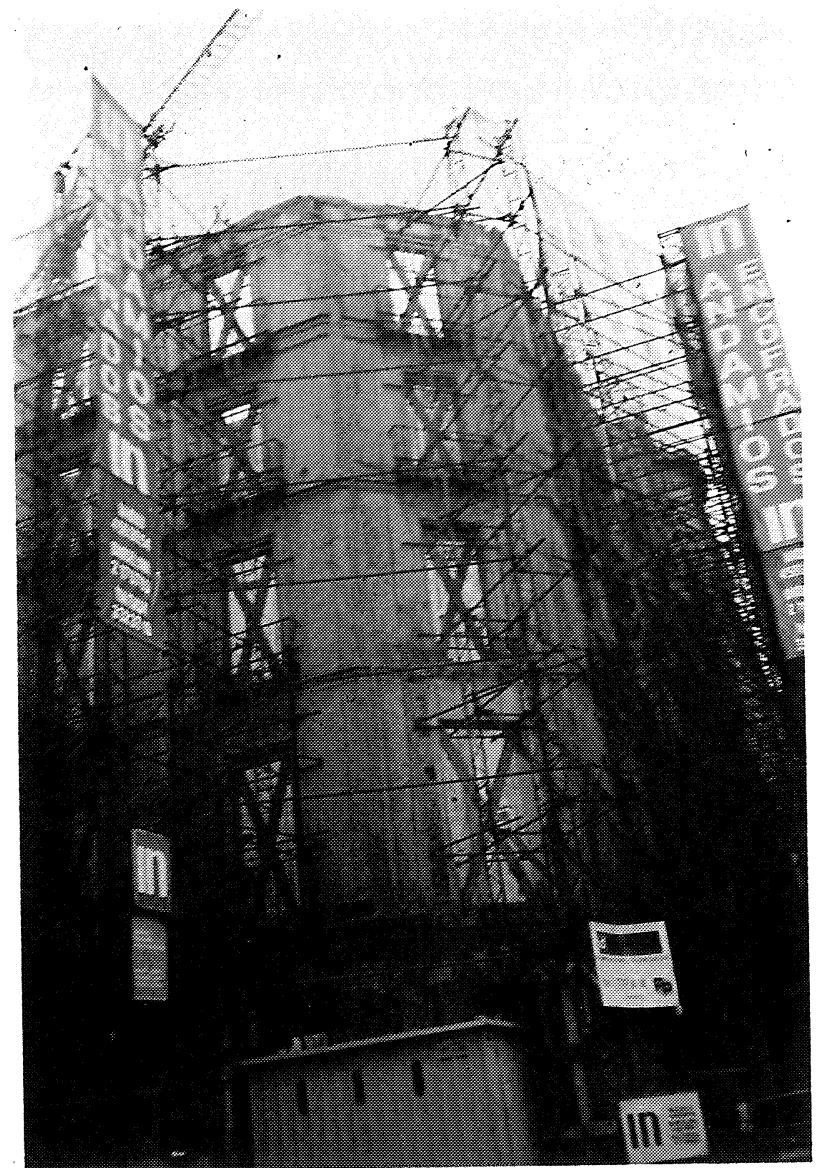

Su construcción es abovedada, en fábrica de ladrillo con arcos rebajados en cañón.

Se ha podido comprobar, después de las calas realizadas, que los cimientos del edificio están integrados con. los propios muros de ladrillo que sustentan la estructura, sobredimensiones en su parte más baja, hasta alcanzar el suelo firme.

Por tratarse de una construcción estructural de muros de carga, las fachadas constituyen en sus alineaciones exterior e interior, dos líneas de apoyo integradas por fábrica de ladrillo macizo con espesores que van de 0,60 a $0,45 \mathrm{~m}$ aproximadamente.

Sobre dichas fábricas, en su cara interior, existe un guarnecido de yeso negro en espesores que oscilan entre 4 y 8 centímetros.

La disposición estructural de doble crujía, apoyadas en las fachadas anterior y posterior, se complementa con un muro central que discurre próximo al eje del cuerpo del edificio.

Este muro está construido en fábrica mixta de entramado de madera y ladrillo macizo, con un espesor medio entre 40 y $30 \mathrm{~cm}$. Con esta técnica están construidos igualmente los restantes muros interiores y tabiques principales del edificio.

El muro central, en las dos últimas plantas, se ha sustituido por un pórtico de tres vanos construido en pérfiles metálicos. 

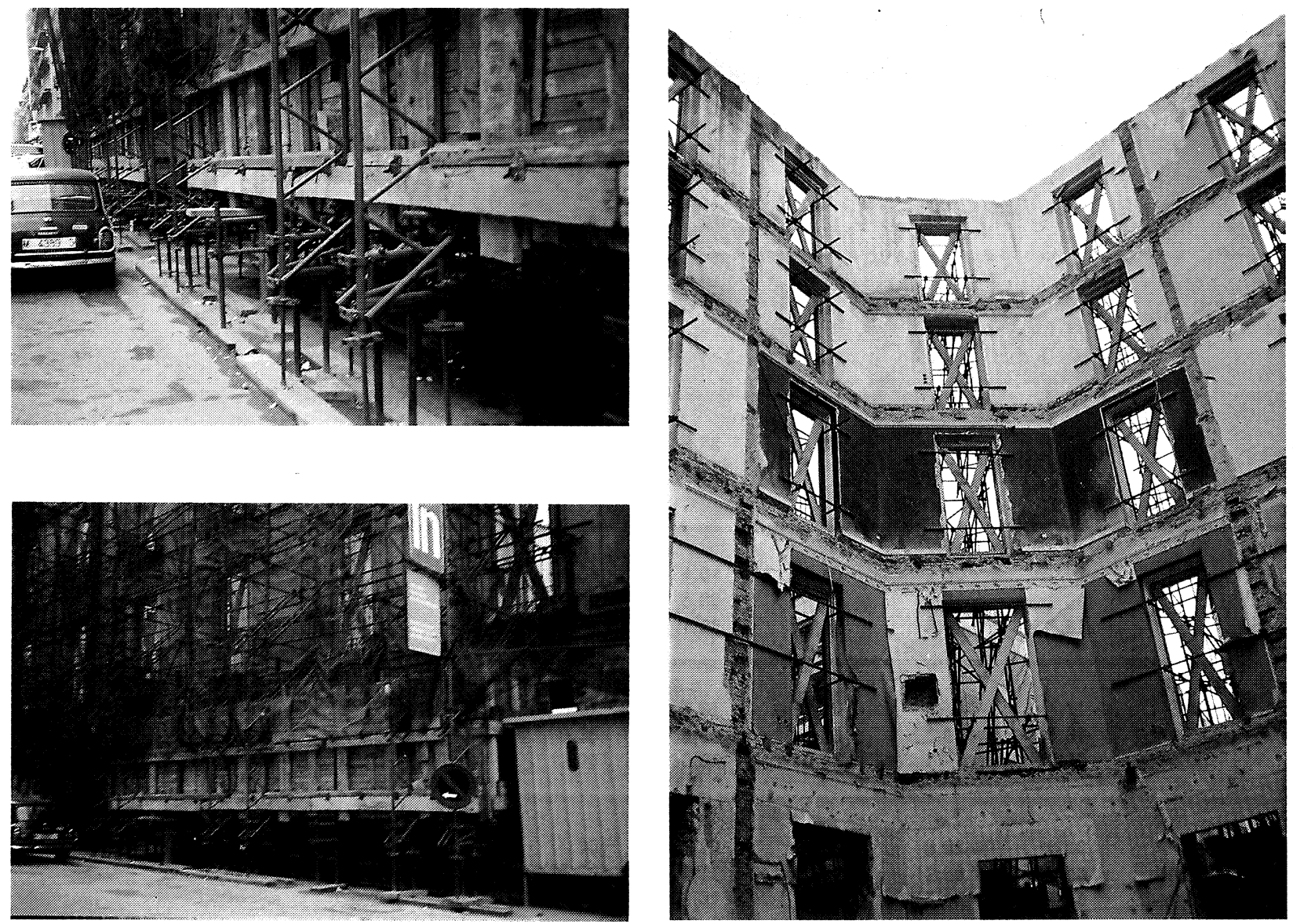

La estructura horizontal de cada una de las plantas está formada por un forjado unidireccional compuesto por viguetas de madera y senos de rasilla y mortero de cal, con rellenos importantes bajo el solado, que según las piezas de su interior, es de baldosa hidráulica o tarima de pino sobre rastreles.

Estos forjados apoyan en las alineaciones de fachada y muro central, con luces que oscilan entre los 7 y 8 metros.

La estructura de la cubierta está compuesta por formas y correas de madera sobre la que se asienta una tarima como plano de apoyo de la teja plana que constituye la cobertura.

Morfológicamente está resuelta a dos aguas, vertiendo a ambas fachadas y con cumbrera en el eje de ambos cuerpos de edificio.

En algunos puntos existen lucernarios para iluminación de los cuartos trasteros y otras dependencias existentes bajo la cubierta.

Coordinación de Obras y Proyectos:

\section{J. M. Frutos}

